\title{
De los Estados nación a los Estados plurinacionales ${ }^{1}$
}

\section{Katherine Mansilla Torres ${ }^{*}$}

\section{Resumen}

En los últimos años, frente a procesos de federalización y regionalización, se ha cuestionado el valor de referencia exclusiva del modelo de Estado nación, y se ha iniciado un intenso debate para legitimar la noción de estado plurinacional o pluricultural. El presente texto presenta un análisis de los límites y las posibilidades de pasar de una a otra concepción de Estado, tomando en cuenta la idea de reconocimiento de las diferencias.

\section{Palabras clave}

Estado, nación, pluriculturalidad, reconocimiento, pueblos indígenas, derechos humanos, democracia, acción política.

\begin{abstract}
In recent years, facing the processes of federalization and regionalization, it has been questioned the value of exclusive reference of the nation-state model, and it has begun a debate to legitimize the notion of multinational or multi-cultural state. This paper presents an analysis of the limits and possibilities of moving from one to another concept, taking into account the idea of recognition of differences.
\end{abstract}

\section{Key words}

State, nation, multiculturalism, recognition, indigenous peoples, human rights, democracy, political action.

Forma sugerida de citar: Mansilla Torres, Katherine. 2011. "De los Estados nación a los Estados plurinacionales". Universitas 15. Julio/Diciembre. Pp 19-52.

$1 \quad$ Este artículo ha sido elaborado y traducido a partir de un texto anterior: A la recherche de la reconnaissance de la plurinationalité au Pérou. Bilan de la politique du gouvernement d'Alejandro Toledo. Mémoire en vu de l'obtention du Diplome d'Etude approfondi. Belgique, UCL, 2007

* La autora es licenciada en filosofia por la Pontificia Universidad Católica del Perú, y magister en ciencias políticas por la Université Catholique de Louvain, Profesora de ética y ciudadanía en la UPC y asistente de cátedra en la PUCP. E-mail:kmansilla@pucp.pe. 


\section{Introducción}

Lo que constituye quizás el elemento más revolucionario de nuestra ciencia del siglo XX (...) es la destrucción total del equilibrio que existía entre teodicea explícita e implícita en el pensamiento occidental y las formas en las cuales se expresan en el transcurso del siglo el sufrimiento y el mal que le es inherente. El siglo que ha conocido dos guerras mundiales en treinta años, el totalitarismo de derecha e izquierda, el hitlerismo, el stalinismo, Hiroshima, el Gulag, los genocidios de Auschwitz y Cambodgia. Es un siglo que está llegando a su fin, con el obsesivo recuerdo del retorno de todo lo que designan estos nombres bárbaros: el sufrimiento y el mal se imponen deliberadamente, pero ningún motivo pone límites a la exasperación de una razón que se ha hecho política y se ha desprendido de la ética (Lévinas, 1991: 34).

Se habla del siglo pasado como de la época en que el pensamiento "moderno" ha comenzado su descomposición. En efecto, como afirma Lévinas, la filosofía occidental moderna ha llegado a la conclusión que existía una razón universal compartida por todos los hombres, fuera de su raza, su cultura, su religión: considerados como individuos racionales, los hombres podían buscar el progreso y la civilización en todo el mundo. En esta perspectiva, las diferencias culturales eran un obstáculo para llegar a un verdadero progreso de la raza humana o simplemente, no eran tomadas en cuenta.

Sin embargo, esta pretendida razón universal no reconocía pertenecer a una cultura particular -occidental-y que sus objetivos no le permitían reconocer la diversidad de pensamientos que habitan el mundo. El imperialismo, los Estados totalitarios, las tiranías han sido justificadas para lograr lo que Lévinas ha llamado "la loca pretensión de lo invisible", es decir una concepción de la superación del ser humano, consistente en decir que encuentra su verdadera libertad poseyendo o destruyendo este otro que es diferente. La razón universal, y puesto que es universal también es única, no puede tolerar la existencia de otra racionalidad, bajo pena de consentir su propia eliminación.

Emmanuel Lévinas y Hannah Arendt han pasado por la trágica experiencia de ser víctimas durante la Segunda Guerra Mundial, causada por la razón universal, en su versión totalitaria. La razón totalitaria, en la búsqueda de la realización de sus proyectos, no ha tolerado la diferencia y ha pensado una 
raza -la aria- como superior a todas las otras. Según Arendt y Lévinas, los pensamientos totalitarios son el producto de un razonamiento formal que ha nacido contra el pensamiento universal para reivindicar una superioridad de raza y de nación. En los dos casos sea a favor o en contra del individualismo, un razonamiento presuntamente universalista ha marcado la tradición filosófica occidental desde Platón. No es fortuito que Arendt y Lévinas hayan pensado la guerra como una acción, que resulta únicamente de un pensamiento que se ha separado de su propia existencia. Esto hace comprender por qué los agentes implicados no han utilizado el diálogo para construir sus teorías y conducir a un buen fin sus acciones.

Después de pasar por estas experiencias, la idea de un pensamiento universal totalitario no es ya concebible, pues nos ha ofrecido un rostro demasiado detestable de los seres humanos, develando su intolerancia y su orgullo. ${ }^{2}$ Con todo ello, a nivel político, la idea de Estado nación se puso en cuestión. Es decir, con este modelo, se tiene un Estado que unifica diferentes culturas bajo un solo modelo de organización política, para hacerlas jurídicamente iguales, pero no toma en consideración las diferencias entre ellas. ${ }^{3}$ De hecho, desde los años sesenta, la política no puede ser pensada a partir de una sola manera de razonar, de una sola posibilidad de organización. En este período han comenzado a nacer colectivos y grupos, que buscan el reconocimiento de sus diferencias al interior de los Estados nación. Son estos grupos minoritarios (colectivos de mujeres, de homosexuales, minusválidos, grupos religiosos, negros, indígenas, etcétera), que exigen una representatividad política y por consiguiente un cambio en las instituciones del Estado, con la finalidad de ser representados, de obtener una autonomía territorial o derechos diferenciales, en otras palabras, de ser reconocidos en su diferencia en términos políticos.

La reivindicación de la identidad particular y del reconocimiento se inscribe en el debate contemporáneo de la filosofía política. Como lo muestra Will

2 El totalitarismo reivindicó creencias nacionalistas en contra de una propuesta universalista de igualdad y libertad, gestada desde la Revolución Francesa.

3 Es interesante analizar las diferentes visiones juristas de los derechos en una perspectiva universalista. Como ha explicado Luigi Ferrajoli (1999) las normas pueden ser válidas pero no necesariamente justas si no consideran un análisis de las relaciones de poder y discursos de poder que se tejen en un interior. 
Kymlicka el reconocimiento de la experiencia de constituir sociedades diferentes al interior de un mismo Estado "induce toda una gama de problemas graves, fuentes potenciales de divisiones. Minorías, mayorías se enfrentan así cada vez con mayor frecuencia en torno a temas como los derechos lingüísticos, la autonomía regional, la representación política, al curso escolar, a las reivindicaciones territoriales, a las políticas de inmigración y de naturalización, incluso a los símbolos de la nación: el himno nacional o los días feriados, por ejemplo. Encontrar soluciones moralmente legítimas y políticamente viables a tales problemas constituye el mayor desafío al que deben hacer frente las democracias en la actualidad" (Kymlicka, 2001: 9).

En este texto concentraré esencialmente la atención en los problemas de legitimidad del Estado nación en cuanto producto de la razón universal de la modernidad. El objetivo de esta parte es defender la idea que el Estado nación no representa ya la realidad política de los derechos de los pueblos en el mundo contemporáneo, y que para tener una política basada en la democracia, la igualdad y la libertad individual el preciso cambiar la visión del Estado moderno. Ello significa que el Estado nación debe ser sustituido por un Estado pluricultural que radicalizando la libertad individual, reconstruye los principios sociales y culturales, a los cuales todos los individuos puedan reconocerse. ${ }^{4}$

El texto presenta tres partes. La primera describe, a manera de un esbozo histórico, cómo el Estado nación ha sido un modelo político basado o en el desinterés a la diferencia o en la opresión y se ha mantenido gracias a una idea de legitimidad fundada en "el poder de la mayoría", es decir que la definición de la legitimidad no se aplicaba a todos los individuos del país, sino solamente a quienes detentaban el poder. La segunda parte explica cómo los Estados han pensado resolver los problemas de las diferencias culturales. La exposición se focalizará en la federalización y la regionalización observadas en ciertos países, indicando sus posibilidades y sus límites, así como las posibilidades de adecuación, que permitan que naciones diferentes mantengan la unidad en un mismo

4 Como ha precisado Axel Honneth (Honneth, 1997), el nivel de la eticidad en la Filosofia del Derecho de Hegel, supone estadios de reconocimiento. Aunque la dinámica dialéctica de los estadios de reconocimiento no se plantean en este trabajo, es importante considerarlos para una lectura del Estado pluricultural, sobre todo para la implementación de políticas públicas en escenarios de posguerra, como se verá más adelante. 
Estado. Finalmente, sin pretender resolver el problema de las diferencias culturales en la política actual, ciertas perspectivas abiertas por la filosofía de Arendt y de Lévinas serán expuestas para clarificar esta problemática al nivel ético. A mi parecer, el pensamiento de estos dos filósofos es introducido en el debate político actual por otros filósofos como Charles Taylor y Will Kymlicka.

Esta tercera parte del texto reposa sobre tres ideas: 1. La necesidad del reconocimiento de la pluralidad como formando parte de la condición humana, explicitada por Hannah Arendt; 2. El reconocimiento de la responsabilidad individual en cuanto referente de una política igualitaria, según lo subraya Emmanuel Lévinas; 3. Las condiciones del reconocimiento en la política actual propuestas por Charles Taylor. La intención de fondo es acercar el debate de la ética contemporánea sobre el reconocimiento a los discusiones constitucionales sobre el Estado pluricultural, vividas - por ejemplo- en Latinoamérica.

Si bien Arendt y Lévinas no forman parte de los debates más actuales de la filosofía política contemporánea, mi intención es partir de estos dos autores por dos razones. La primera es, según mi opinión, que ellos han hecho notar la ilegitimidad del Estado nación en los modelos ético y políticos de la modernidad y plantearon ciertas perspectivas que podrían ser consideradas para los debates constitucionales latinoamericanos. La segunda razón es que considero que su punto de partida es el rechazo a la violencia, lo que los hace muy cercanos a la experiencia política peruana, sobre todo después del periodo de violencia interna (1980-2000). Hannah Arendt, Emmanuel Lévinas y Charles Taylor aportan un marco teórico para comenzar a entender por qué en el Perú las políticas pluriculturales permanecen ausentes y la evaluación de las mismas no es tomada en cuenta por sus representantes políticos. ${ }^{5}$

$5 \quad$ El presente trabajo se enmarcaba en un estudio profundo de las políticas públicas con ciertas características "pluriculturales" e "interculturales" ejecutadas durante el gobierno de Alejandro Toledo (2001-2006), después del período de violencia interna y des-institucionalización democrática con Fujimori. Cinco años después de escribir este texto, el Perú no ha iniciado sustanciales cambios para el reconocimiento de la diferencia de sus pueblos, a pesar de haber reconocido jurídicamente la Carta de la OIT 169. No obstante, han aumentado el número de conflictos socio-culturales, como lo plantean los informes de la Defensoría del Pueblo (2010). 


\section{La legitimidad del Estado nación}

Max Weber define el poder como "toda oportunidad de hacer triunfar en el seno de una relación social su propia voluntad incluso contra sus resistencias" (Weber, 1971: 67). De hecho, para Weber el poder es la relación de influencia de un actor (o un grupo de actores) sobre los otros. Esta relación entre la autoridad y sus subordinados está marcada por la asimetría, ya que los actores no tienen la misma fuerza cuando se trata de tomar decisiones. Es la autoridad que tiene la fuerza necesaria para que los otros acepten hacer lo que ella quiere. ¿Cómo la relación de poder ha evolucionado de esta manera? Porque el poder de una autoridad es siempre la representación de los deseos colectivos, de las reglas y de los valores que la comunidad quiere ver realizados. Esto es lo que legitima el poder: son los subordinados los que ponen en su autoridad el manejo de la fuerza, por libre elección.

Es preciso explorar ahora la relación entre poder y nación. Para Kymlicka, el concepto de "nación" remite a una "comunidad histórica más o menos institucionalizada, que ocupa un determinado territorio, o su tierra natal, y comparte una lengua y una cultura específicas" (Kymlicka, 2001: 25). Él relaciona este concepto con el de "pueblo" y de "cultura". Luis Villoro define la idea de nación como 1. El hecho de ser una comunidad que comparte una misma forma de ver, de sentir y de actuar en el mundo, y 2. El hecho de tener conciencia de pertenecer a una misma historia (Villoro, 1999: 13). Estas dos primeras características coinciden con la idea de Kymlicka. Entonces, se puede pensar que el poder representa las creencias colectivas de los grupos culturales a partir de su propia historia y que la legitimidad del poder está atribuida por la común aceptación del pueblo o de la nación. Ello significa que la nación da la legitimidad del poder a la autoridad, pues la autoridad representa en ocurrencia valores de la nación.

Pero Villoro añade otras dos características a la idea de nación, que evoca al referirse a la idea de "proyecto". Desde este ángulo, la nación consiste en 3. Tener un proyecto común a partir de una interpretación de la historia, y en 4. Compartir un mismo territorio. Estas dos características se acercan, sobre todo, a la idea de nación de la época moderna, donde ha nacido la figura del Estado nación como modelo legítimo de poder y de la representatividad nacional. 
En el Estado moderno la nación es sobre todo un proyecto y el Estado es el agente de este proyecto. Antes del siglo XVIII, el poder se fundaba sobre "la fuerza de los más fuertes" o sobre "la herencia divina". Desde la constitución de los primeros Estados, el poder se fundó sobre las reglas y los principios de la libertad y de la igualdad entre individuos racionales, que son capaces de tomar decisiones sin considerar sus comunidades de pertenencia. Cuando los valores de la cultura occidental no se encuentran ya al interior de la comunidad, sino en cada individuo, es preciso modificar el tejido social y político: los valores se transforman en un proyecto político y social, la historia no se interpreta, como en el pasado, como la continuación de lo que ya existía sino más bien como lo que los hombres pueden hacer en el futuro.

De esta manera, la nación occidental pone el acento sobre la idea de nación como proyecto y no como historia, como pertenencia. En esta perspectiva, el Estado se convierte en un modelo de poder, que se identifica con la nación. Es la invención moderna: el poder legítimo es el Estado nación que representa un razón universal compartida por todos los hombres, al margen de sus comunidades particulares, sin reconocer las diferencias entre los pueblos.

Hay que recordar que para Thomas Hobbes la única posibilidad para cada individuo de hacer uso de su libertad natural consiste en restringir la libertad de los otros hombres: en un mundo de seres miserables y envidiosos -el mundo de los hombres- es necesaria una entidad que centralice el poder (Hobbes, 1984). Es el Leviatán quien crea el miedo, pero también, la unificación entre los hombres. La autoridad política, el Leviatán, se impone por encima de todo individuo para mantener el orden. El proyecto de Estado nación no busca la conservación de la unidad de un territorio, defendiendo la libertad de los individuos, que pertenecen a diferentes comunidades. El Leviatán se convertirá, por consiguiente, en el Estado nación, el poder máximo que la razón humana haya creado durante la Modernidad: el sistema político gracias al cual la autoridad central recluta los ejércitos, exige los impuestos, concentra la población bajo una misma bandera, una misma lengua, las mismas creencias. A cambio, esta autoridad garantiza seguridad y prosperidad a sus ciudadanos (cfr. De Rivero, 2001).

Después de la Revolución Francesa y la primera declaración de los Derechos del Hombre, la idea de Estado nación toma más fuerza. El poder no se 
concede a un grupo de ciudadanos o a una persona en particular, como Hobbes había pensado. El cambio consiste aquí en que el Estado nación comienza a representar la totalidad de los ciudadanos que componen la nación. La legitimidad del Estado nación es la asociación de todos los individuos que por su propia voluntad han decidido compartir el proyecto político de la soberanía. ¿Quien detenta el poder legítimo? El Estado nación, pues representa la comunidad de hombres libres, iguales entre ellos y capaces de tomar decisiones. Por eso, la sociedades occidentales consideran los Estados nación como fundados sobre la "voluntad general del pueblo", como Rousseau lo había ya mostrado (cfr. Rousseau, 1762).

Con el proyecto de Estado nación, de cierta manera, la memoria histórica particular de cada pueblo se pone entre paréntesis, o sufre un olvido. El derecho moderno crea la idea del derecho natural, a partir del cual los hombres nacen libres e iguales entre ellos. En el derecho natural, la distinción cultural no presenta interés alguno dentro del proyecto de construcción de los Estados nación. Así, los individuos se piensan políticamente según la ley igualitaria y no consideran el derecho de ser diferente. Todos los individuos buscarán ser tratados como los otros y gozar de los mismos privilegios. Cabe recordar, por ejemplo, como en 1791, Francia celebra la fiesta de la Federación, en el curso de la cual todas las autoridades se pronuncian por la homogeneización de los pueblos ante la ley de la "nación francesa", entre las cuales se reivindica una sola lengua y la forma de enseñarla.

Pero, la gran ventaja de la teoría moderna es que del reconocimiento de la igualdad individual nace también el reconocimiento de la diferencia. Sin embargo, esta preocupación no aparecerá sino más tarde y solamente después que la experiencia ha enseñado que la universalización, bajo su forma última, genera la opresión. Por ello, hay que explorar ahora cómo se ha podido desarrollar una política legítima de opresión de los pueblos minoritarios en nombre del Estado nación y de su pretendido razonamiento universal.

Sin considerar la pertenencia cultural, el deber de todos los individuos consistió en integrarse a las leyes universales, celebradas en el contrato social. Pero lo que los teóricos modernos no podían ver es que la forma de la ley universal albergaba también características propias de la cultura hegemónica: la de la cultura occidental, cristiana, masculina, burguesa que se impone a todos en una 
unidad de lengua, de educación, de procesos jurídicos, económicos y administrativos (Villoro, 1999:25). Estas formas estaban legitimadas por el poder central, el poder de la mayoría de los ciudadanos, que compartían la misma lengua y las mismas tradiciones.

Sin embargo, no todos los ciudadanos se organizan de esta manera. A pesar de esta realidad, los pueblos minoritarios se han adaptado a las formas de la mayoría. El caso español, por ejemplo, ilustra cómo el pueblo vasco o el pueblo catalán han debido aprender el castellano y han debido estudiar la historia castellana "olvidando" su propia historia. El caso de Francia nos muestra cómo la Tercera República impone que una única lengua sea hablada sobre todo el territorio.

Por lo tanto, el trabajo del Estado nación consistía en incorporar las minorías en la cultura de la mayoría. La cultura hegemónica imponía sus modos de vida y legitimaba el poder político en la medida que los ciudadanos adquirían a cambio los derechos de la libertad, aunque algunos no los hubieran pedido o deseado.

De esta manera ha nacido la primera forma de "resolver" los problemas de las diferencias culturales: es "la asimilación" o lo que en inglés se conoce con el nombre de melting pot. ${ }^{6}$ En esta perspectiva se estima "que la asimilación es un factor esencial de estabilidad política, al fundarse en argumentos afectados de etnocentrismo y en el denigración de las culturas" (Kymlicka, 2001: 28). Los Estados nación sostienen que el particularismo local debe ser disuelto para hacer valer una presencia "nacional", que es de hecho la cultura dominante. Todas las diferencias son eliminadas en la perspectiva de la estabilidad nacional. Este es el gran proyecto moderno.

\footnotetext{
6 No hay que olvidar que frente a la asimilación, hay otros modos más inhumanos como la depuración étnica, la expulsión masiva o el apartheid que implican la segregación física, económica y política de una comunidad del territorio. Como se ha indicado al inicio del texto, el siglo XVIII y XIX abundan en acontecimientos que expresan bien esta realidad de discriminación y racismo. Los países latinoamericanos son un caso particularmente complejo: ellos han creado un Estado, que no ha reconocido los pueblos indígenas como naciones. Por ejemplo en el Perú, los pueblos indígenas fueron importantes gestores de la independencia, pero o no fueron considerados ciudadanos de la naciente república o fueron considerados "ciudadanos de segunda" (uso el término a propósito de las declaraciones del Presidente García frente a los conflictos de Bagua 2009, cfr: <http://www.youtube. $\mathrm{com} /$ watch?v=3ekPeb6nMnw>) Consulta: junio 2009 .
} 
La asimilación se ha ejercido sobre todos los grupos minoritarios, ya sean migrantes, como en los Estados Unidos, o en Canadá, o que hayan habitado siempre este territorio (autóctonos). Tal fue el caso de las comunidades indígenas de América Latina: la fiebre del Estado nación alcanzó también a las colonias españolas y portuguesas. La independencia es entonces buscada no para todas las poblaciones, sino solamente para la población criolla hecha de hijos españoles nacidos en el territorio latinoamericano. Los grupos latinos que tenían el poder político después de la independencia no tenían una idea ni un sentimiento de nación, de cultura compartida con las culturas nativas. Los grupos latinos en el poder han construido el Estado "sin nación" y si algunos han pensado construir una nación, solo han copiado las características culturales de los países europeos, "rechazando" las características autóctonas. Entonces, o bien existe un "Estado sin nación" o hay un "Estado nación híbrido" inventado y reflejado en el proceso histórico de sus colonias y no propio. Es de esta manera que las repúblicas latinoamericanas construyen un modelo de comunidad política extranjera al concepto de nación, pero sin tomar en consideración tampoco el pluriculturalismo, las creencias, las lenguas, las religiones de su vasto territorio. Este modelo no se limita a copiar una forma de organización político administrativa que no incluye en la sociedad, de manera democrática, a quienes en realidad formaban "la nación".

En consecuencia, los valores que el Estado defiende son elegidos únicamente por el grupo que conforma la cultura predominante. En el caso de los países latinoamericanos, la jerarquía colonial ha permanecido intacta después de la independencia. De hecho, la cultura "criolla" toma posesión del Estado; sus miembros deciden los valores, los principios y las reglas del país. Por el contrario, las culturas indígenas deben ocultar sus costumbres, hablar español, imitar a los criollos. A pesar de la pérdida de sus culturas, los miembros de las comunidades indígenas no son considerados como ciudadanos, no gozan de las mismas condiciones de vida. Ser indígena es un criterio de exclusión política, económica y cultural: "la República hereda el horizonte mental colonial y así la elite criolla asume el poder. La construcción de la nación pasaba por la desaparición de los indios, en algunos caso su desaparición biológica, si no por la exterminio o la dominación, por el mestizaje biológico con "razas superiores" cuya atracción debía estar asegurada por sabias políticas de inmigración, o de 
manera cultural por la des-indigenización, que debía quedar asegurada a través de la educación y la evangelización" (Manrique, 2001).

Obviamente, el término de "voluntad general", término resultado de la Modernidad, sufre un desfase entre la teoría y la realidad, puesto que una nación no puede encarnar los deseos de naciones diferentes. ¿Cómo resolver esta dificultad? J. Stuart Mill, por ejemplo, piensa que la solución consistiría en que los Estados nación sean realmente representativos de una sola nación y no de otras (cfr. Mill, 1972). El autor decía que en una democracia, las instituciones deben representar solamente los deseos y valores de una nación en particular, y que es imposible compartir o representar la diferencia. Sin embargo, Mill deja entrever que entre los Estados nación se encontrarán diferencias de "civilización" y que puede haber Estados nación más civilizados que otros, debido a características propias de sus culturas.

Mill no considera la plurinacionalidad como un problema; piensa más bien que es necesario separar los Estados plurinacionales en diferentes Estados. El concepto de "civilización" implica la superioridad de ciertas naciones sobre otras, lo que deja entrever los conflictos causados por nacionalismos extremos. De hecho, el Estado nación alemán de Hitler se ampara de la idea de civilización de Mill, para pensarse superior a las otras naciones, en particular a los judíos y gitanos. Y sabemos lo que han producido los pensamientos ultra-nacionalistas y cómo fue utilizado el poder de Estado para oprimir otros pueblos. Después de la Segunda Guerra Mundial, los derechos del hombre pusieron el acento sobre la protección de los pueblos minoritarios. Actualmente, la política universal se hace bajo la defensa de estos derechos (los derechos culturales, los derechos de los pueblos) y busca una vía para establecer el poder más representativo.

Es importante, sin embargo, preguntarse si los derechos del hombre son suficientes para poner en práctica los derechos culturales. Para responder a esta cuestión podemos distinguir diversas modalidades seguidas por los Estados, que se reconocen actualmente como plurinacionales, para encontrar una manera de mantenerse unidos y al mismo tiempo respetar y valorizar sus diferencias culturales internas. 


\section{El reconocimiento de los Estados plurinacionales y la implicación de sus cambios políticos}

El Estado nación ha otorgado igualdad y dignidad a todos los individuos sin interesarse a sus diferencias culturales, pero acabamos de ver que esto no era suficiente para llegar a pensar el poder como igual y democrático, para decir que el poder político es realmente legítimo. El problema del Estado nación es que uniformiza y da una hegemonía a un grupo, que dicta la manera de vivir en sociedad. Pero esta manera no es compartida por todas las comunidades y las culturas que habitan el país.

Actualmente ciertos países en el mundo se reconocen como plurinacionales, pues a partir del reconocimiento de los derechos del hombre y de los pueblos, algunos países han modificado su constitución o han creado normas y leyes, para que todas las naciones puedan desarrollarse equitativamente. ${ }^{7}$

Es necesario, sin embargo, interrogarse: ¿son suficientes los Derechos del Hombre como base fundamental para que cada Estado adopte medidas a favor de las particularidades de los pueblos minoritarios? Generalmente, los derechos humanos no han sido pensados para defender al "particular", porque éste no es "el individuo en cuanto tal", que es justamente considerado por los derechos humanos precisamente concebidos como transcendiendo las comunidades particulares. Pero -quizás- a veces los derechos de identidad cultural suponen una oposición con las particularidades de los individuos. Según Xavier Exteberria, "la relación entre derechos humanos y el pluriculturalismo es compleja, de un lado, se relativiza cuando ciertas personas piden considerar un ser humano como tal: de otro lado, la relación es favorecida cuando otros piden respeto y condiciones equitativas entre las culturas" (Extebarria, 2006).

Este problema requiere el análisis de numerosos elementos. Pero se puede pensar esta discusión en términos de legitimidad del Estado: ¿Qué hace más legítimo un Estado, en términos de democracia liberal, de tal suerte que esta sea más representativa, o más participativa? ¿Cómo un Estado que se reconoce plurinacional puede definir las condiciones necesarias para que todos sus

7 Es importante considerar aquí los diferentes cambios que se han ido en la concepción de los Derechos Humanos. 
ciudadanos puedan sentirse como parte de una nación y al mismo tiempo de un Estado?

Se puede pensar que algunos Estados han preferido dar razón a J. S. Mill, puesto que se han separado de un Estado nación y forman actualmente pequeños Estados nación. Por ejemplo, Yugoslavia se ha transformado en seis repúblicas (Servia, Bosnia, Croacia, Macedonia, Eslovenia y Montenegro). Pero hay otros países que han privilegiado una modalidad consistente en mantener juntas diferentes naciones y así encontrar soluciones para que sus lenguas, sus culturas, sus formas de vida sean representadas en cada institución del Estado. Los países que han desarrollado medidas que permiten que la política sea un espacio de reconocimiento cultural han optado frecuentemente por el federalismo o el regionalismo.

Suiza, Canadá, India son Estados federales. El federalismo ha sido una perspectiva política en respuesta a la discriminación. Esta forma de Estado ha sido elegida, precisamente para que "permita regular o atenuar los problemas nacidos de la heterogeneidad étnica, religiosa o lingüística de la población y la existencia de minorías. El recorte territorial y político del federalismo puede igualmente ser útil a las minorías, cuando éstas, sin ser suficientemente importantes y concentradas como para obtener la mayoría en su Estado de residencia, sí lo son para ejercer en él una fuerte influencia política" (Woehrling, 2005).

Por otra parte, los Estados regionalizados, como España o Italia tienen otra manera de afrontar su diversidad étnica. En España por ejemplo, el gobierno central ha dividido el poder otorgando la autonomía jurídica, económica a los territorios vasco, catalán y gallego a través del poder municipal o regional.

El federalismo y el regionalismo permiten a ambos que el poder local sea más legítimo que el poder ejercido a nivel del Estado nación, ya que: 1. El poder dividido da la posibilidad de una mejor participación democrática de los ciudadanos y de las instituciones más eficaces al servicio de pequeños grupos de ciudadanos; 2. Puede ejercerse un mejor control de los abusos y también una prevención contra las violaciones de los derechos humanos; 3. La descentralización económica proporciona más autonomía al territorio.

En resumen, el federalismo y el regionalismo buscan un poder más equitativo, que permite a cada parte del territorio, dividido según las naciones correspondientes, encontrar sus propias formas de desarrollo y al mismo tiem- 
po participar en el proyecto político-económico del Estado federal. Por esto, los Estados federalistas pueden desarrollar y mantener sus recursos históricos como culturas, y al mismo tiempo participar al proyecto moderno y de la organización de un Estado más poderoso.

Sin embargo, el federalismo y el regionalismo se han establecido a partir de una lógica fundada sobre una concepción del territorio que supone que las naciones se encuentran en territorios que pueden ser bien delimitados. Tal es en efecto el caso de España donde las poblaciones: catalana, vasca y gallega ocupan territorios específicos. Pero ¿qué ocurre si las naciones no están reagrupadas en un territorio específico sino dispersas en todo el país, como es el caso de pueblos nativos en latinoamérica que han migrado y se han dispersado? ¿Cómo son protegidas las minorías de un territorio de la misma manera al nivel de las regiones o de la federación? Hay un límite para no pensar el federalismo más que a nivel territorial. ¿Cómo pensarlo tomando en cuenta las minorías de todos los pueblos y no solo de los pueblos mayoritarios?

Otros países han encontrado un mecanismo diferente del federalismo. Este nuevo modo de organización se llama federalismo personal. Es decir, se trata de un mecanismo que reconoce que las personas están vinculadas a una comunidad por sus características personales como la lengua o la religión. Es el caso de Bélgica o de Líbano.

En Bélgica, por ejemplo, hay una división al nivel de los territorios con tres regiones (Flandes, Wallonie y Bruselas), las cuales están a cargo de todo lo que concierne el territorio (medioambiente, agua, energía, transporte, empleo, economía, comunicaciones, comercio), y tres comunidades lingüísticas (alemana, flamenca y francesa), que están a cargo de las "culturas lingüísticas (turismo, salud, enseñanza, protección de la juventud). En el caso de Bruselas, puesto que se trata de un territorio compartido por flamencos y walones, son medidas más específicas del federalismo personal que se aplican: la comunidad es definida por las "personas" y no por los territorios. Es decir, las instituciones son subvencionadas o por la comunidad flamenca o por la comunidad walona. El ciudadano puede elegir a qué institución pertenecer. Sin embargo la realidad es que las regiones territoriales tienen poderes más importantes que las comunidades lingüísticas. 
En el caso de Líbano, el federalismo personal propone respetar y garantizar los derechos religiosos de todos los ciudadanos. Así, las comunidades religiosas tienen el derecho de someter sus miembros a un estatuto personal, que les es propio y crear jurisdicciones competentes en materia de matrimonio, de divorcio, de adopción y para todos los otros aspectos de la vida relativos al estatuto personal. Pero "las tentativas de organizar un federalismo personal han quedado hasta ahora muy modestas: se enfrentan al hecho que los sistemas democráticos modernos funcionan sobre la base de una representación política y de criterios de aplicación de leyes basados esencialmente sobre el territorio" (Woehrling, 2005: 9).

De otro lado, el solo reconocimiento de una autonomía territorial acarrea siempre el riesgo de que cada nación haga prevalecer sus intereses sobre los intereses del Estado plurinacional. El problema de fondo en este tipo de forma de Estado no es el reconocimiento entre una y otra nación sino simplemente la tolerancia entre ellas, ausentes de debates para buscar puntos en común. La tolerancia es un valor importante cuando se trata de conseguir la paz y preservar la democracia al interior de los Estados, pero no ayuda a unificar las naciones de un mismo Estado.

Estas naciones se baten fundamentalmente por la autonomía. La relación entre las naciones está condicionada por los intereses de cada nación, aun cuando estén definidos como un conjunto corporativo de naciones. No podemos hablar entonces de un interés respecto del otro en tanto que diferente, sino más bien de un interés respecto de que existe para ayudarme a hacer algo. La tolerancia favorece el respeto de la autonomía pero no la integración entre diferentes pueblos en un mismo Estado.

Como lo ha declarado Kymlicka a propósito del separatismo, "los Estados democráticos multinacionales que reconocen un derecho a la autonomía a sus minorías se muestran inestables, de manera inherente, por esta misma razón. Más bien parecen no corresponder más que a una suerte de modus vivendi entre diferentes comunidades, sin vínculos intrínsecos, que justificaran que los miembros de un grupo nacional aceptan hacer sacrificios en beneficio de los miembros de otros grupo" (Kymlicka, 2001: 257). 
Si según Wieviorka una primera manera de conferir una legitimidad al Estado es la "asimilación", una segunda manera se arraiga en la "tolerancia". ${ }^{8}$ En la perspectiva de la tolerancia se sostiene que es necesario tolerar la diferencia, pero de tal manera que ello no perturbe el orden público y no genere violencia o conflictos. Es decir, que es posible que un Estado abrace diversas naciones que son capaces de vivir juntas, de compartir objetivos comunes, de unificarse políticamente y económicamente: es el proyecto de un Estado que funda la existencia de la diferencia en la autonomía y no va más allá.

Podemos continuar apoyándonos en la posición de Kymlicka: "Suponiendo, dice, que la autonomía local disminuye el riesgo de violencia, los arreglos que proceden constituyen raramente ejemplos de cooperación armoniosa entre grupos nacionales. Éstos se convierten con frecuencia en "simples tratados de cooperación", en virtud de los cuales grupos en litigio "aceptan cooperar para un número limitado de problemas, si esta cooperación es solo posible. El sentimiento de solidaridad requerido para promover el bien común y la justicia simplemente falta. Esto resulta cada vez más verdadero en Bélgica y en Canadá" (Kymlicka, 2001: 263). Desde entonces se ve observa que la tolerancia entre pueblos y las tácticas puestas en práctica para "cooperar" con la finalidad de obtener beneficios particulares por el federalismo no son suficientes para pensar el Estado como poder realmente legítimo en el marco de la diversidad cultural.

De ahí la cuestión ¿cómo pensar un Estado plurinacional? ¿Cuáles son las bases para mantener un Estado plurinacional que afirme las diferencias? Ciertos filósofos, entre ellos John Rawls, ha pensado que un Estado plurinacional puede existir gracias a los "valores" que todos los ciudadanos comparten. Según este autor, el valor de la justicia genera un vínculo de identidad entre las culturas (Rawls, 1977. cfr. Rawls, 2006). Esta idea de justicia tiene como contenido la obligación de defender los derechos humanos y los valores individuales. Pero no es evidente que la justicia pueda estar a la base de la existencia de uno o muchos Estados, puesto que actualmente casi todos están comprometidos para respetar y vivir de acuerdo con los derechos humanos. Se pueden respetar

8 Wieviorka 2006. Según el autor hay tres maneras de considerar la existencia de un Estado plurinacional: 1. La asimilación (la más discriminante), 2. La tolerancia; y 3. El reconocimiento. Yo utilizo esta división para comprender las posibilidades y los límites de los Estados actuales. 
los mismos principios sin que haya necesidad de seguir viviendo políticamente juntos. De otro lado, la idea de justicia puede variar de una nación a otra, todo depende de la historia de cada pueblo, de las apreciaciones y de los deseos colectivos que delimitan lo que es justo o injusto.

Por otra parte, Will Kymlicka indica que el ingrediente susceptible de ayudar a la construcción de un Estado plurinacional puede ser la "identidad común” (Kymlicka, 2001: 255). Pero esta noción es también difusa. ¿Qué es la identidad común? Para algunos países la identidad puede basarse en la historia compartida entre todas las naciones. Sin embargo, se puede considerar que en una misma nación la identidad nacional es una construcción "imaginaria" y que en ocasiones está al servicio de los grupos dominantes. Por ejemplo, se cuenta la historia de una nación de una cierta manera para obtener beneficios y dar una legitimidad a las acciones políticas emprendidas (es el caso del nazismo cuya ideología se funda sobre la construcción de un mito). En otros casos, la historia puede contemplarse de maneras diferentes según los grupos dominantes y la mayoría de los no-dominantes. Por ejemplo, los grupos minoritarios de Canadá pueden contar la historia de una manera muy específica. En los Estados multinacionales ¿cómo pueden enorgullecerse de la historia de un Estado, cuyas poblaciones son diferentes y generalmente no se conocen?

Charles Taylor propone una nueva perspectiva con la noción de "diversidad profunda", es decir la aceptación por cada individuo de pertenecer a una "diversidad de naciones", que constituye un "estímulo y un motivo de orgullo" para conservar la identidad (cfr. Taylor, 1992). Esta última proposición está en relación con la voluntad de cambiar las instituciones y proponer en su lugar un Estado plurinacional, en el que las instituciones democráticas representarían legítimamente la diversidad social y cultural.

El interés de este cambio es que el reconocimiento de la diferencia es un sujeto que se discute en el sentido de la sociedad civil. En el espacio público, "se reconoce al otro como portador de intereses y de derechos legítimos, lo que quiere decir que el espacio público produce una cultura democrática" (Tubino, 2004). Actualmente diversas organizaciones han logrado cambiar leyes y políticas a favor de la diversidad. El espacio público supone que los debates tienen lugar entre actores iguales, y que todas las decisiones son el fruto de consensos 
(y no ya el resultado de la mayoría como era el caso en el funcionamiento clásico de la democracia).

Pero el postulado de Taylor supone una "voluntad profunda", que no es compartida por todos los miembros de los Estados plurinacionales. Para valorizar la diversidad, cada persona debe, en primer lugar, valorizar los grupos étnicos nacionales y, para tener este nivel de compromiso los ciudadanos deben conocer un poco la realidad de cada comunidad. La voluntad necesaria para una tal apertura se sitúa muy alta y supone un nivel ético de valores (el compromiso, la solidaridad), que precede el nivel político.

Lo que se ha expuesto hasta aquí nos muestra que la filosofía política requiere volver a un nivel de la ética, que constituye la base de toda construcción política, de toda significación de organización de las naciones. Es por consiguiente posible que el tipo de acercamiento propuesto por una étnica nos proporciona el marco teórico susceptible de dar una real legitimidad a los Estados plurinacionales.

\section{Marco ético para el reconocimiento de la diferencia: las condiciones del reconocimiento}

En esta parte querría indicar cuatro ideas claves, que la filosofía y la ética contemporáneas nos han proporcionado, tras el final del pensamiento "moderno" y la Segunda Guerra Mundial.

A la luz de estas ideas aquí expuestas podríamos comprender lo que la política contemporánea debería tomar en cuenta para pensar la legitimidad de un poder basado en el reconocimiento de la diversidad cultural. Dicho de otra manera, indico los elementos éticos que -a mi parecer- deben estar presentes en las decisiones y la organización del Estado. Estas ideas serán, por otro lado, instrumentos para comprender la realidad pluricultural del Perú y los problemas que plantea, si se quiere llegar al reconocimiento de las minorías culturales. Sin tener la pretensión de exportar los modelos políticos de otros países, ni interpretar la historia peruana paralelamente a la realidad de Europa o de los Estados Unidos, los postulados que se presentarán aquí son relativamente más cercanos de la historia por la que ha atravesado el Perú durante los veinte últimos años, ya que resultan de una experiencia histórica violenta y dolorosa. En 
este sentido, querría partir de estos conceptos para pensar cómo los elementos, que ponen en valor están presentes en la historia de la diversidad del Perú y nos proporcionan orientaciones sobre las posibilidades de integración del país al nivel político.

Estas cuatro ideas son presentadas en relación a tres filósofos: Hannah Arendt, quien nos dará la definición de lo que es la pluralidad política, Emmanuel Lévinas quien nos introduce en el tema de la significación de la responsabilidad hacia el otro, y Charles Taylor, quien abre dos perspectivas complementarias a las anteriores, a saber, las nociones de memoria histórica y de horizontes compartidos.

\section{La pluralidad, una condición humana (Hannah Arendt)}

Hannah Arendt propone como antídoto a los regímenes totalitarios (como el nazismo), una sola vía posible al nivel político: la acción, "la única actividad que pone directamente en relación los hombres, sin la intermediación de los objetos ni de la materia. Ella corresponde a la condición humana de la pluralidad, por el hecho de que son los hombres y no el hombre que viven sobre la tierra y habitan el mundo" (Arendt, 1983: 41). En otros términos, para la autora, la pluralidad es una condición humana, en cuyo seno se desarrolla toda acción. No podemos pensar acción política alguna sin el reconocimiento de la diversidad, la pluralidad es la condición de la acción humana, es la de nuestro criterio de semejanza: "Esta pluralidad es específicamente la condición humana - no solo la condición sine qua non, sino más bien la condición per quam de toda vida política" (Arendt 1983:41). Entonces, para Arendt la acción no puede ser realizada más que tomando en cuenta la diversidad humana.

Arendt refunda así el concepto de pluralidad, junto a las otras dos condiciones humanas que son la vida y la muerte. En toda la filosofía, la pluralidad nunca ha tenido una significación tan radical, porque en la pluralidad (política, cultural) estará el origen de toda acción y de toda decisión política. No podemos pensar la política sin pluralidad, no podemos pretender un modelo político unitario (asimilación) ni estrictamente dividido para cada humano, puesto que toda forma política implica la igualdad y, al mismo tiempo la diferencia. La igualdad, pues todos los ciudadanos tienen acceso al espacio público y a la ley. 
La diferencia ya que todos los ciudadanos se comportan de acuerdo al ethos al que pertenecen. Por consiguiente, en esta concepción del espacio público, no hay lugar para una reducción a lo idéntico y a lo invariable.

En la filosofía de Arendt se encuentra una idea importante: la que consiste en considerar el espacio político como anterior a toda forma de Estado (el pueblo hebreo existía antes del Estado de Israel), espacio político que no es concebido en cuanto geográfico sino como lugar de acción, donde todo se reúne y se separa. Es la fuerza de la palabra "between", que utiliza la filósofa, como la doble función política de reunir las personas entre sí y separarlos de una forma articulada. En efecto, “el espacio público no podría existir sin este frágil equilibrio de la proximidad y la distancia, tan alejado de las falsas fraternidades fusionales de un igualitarismo totalitario como de los modelos de jerarquías que reservan a uno o a algunos la posibilidad de actuar. Es solo en el intervalo entre la indiferencia de la unanimidad y las disparidades de la desigualdad, que puede surgir una dimensión de pertenencia y de comunidad. Tal es el sentido de esta igualdad que se propone poner fin a toda dominación política por el reconocimiento de las diferencias y no por la uniformización" (Enegrén 1984: 47).

En resumen, ¿qué nueva perspectiva se puede sugerir a partir de la noción de pluralismo de Arendt? Considerar la política como un campo de acción plural; no hay otra posibilidad. Esta pluralidad obliga a todos los ciudadanos a reconocerse en sus diferencias (como lo piensa también Taylor), y a construir los marcos políticos, las leyes, las políticas públicas teniendo en cuenta estas diferencias. En este sentido, ni la asimilación ni la tolerancia obtienen resultados que estén al nivel de una ética intersubjetiva; solo alcanzan un nivel de reconocimiento en el cual la acción (que implica el "entre" de Arendt) no se ha manifestado. La asimilación y la tolerancia son formas de coexistencia del hombre moderno. Pero lo que nos dice Arendt va más allá: es necesario actuar en política pensando que todos son diferentes y que los resultados, que hacen objeto de normas no pueden ser más que la expresión de un consenso.

Por ello, la idea de J. S. Mill, que no concebía que una nación pudiera componerse de muchas culturas diferentes no se articula a las nociones contemporáneas de formas de Estado, pues vivimos en un espacio donde todos los ciudadanos son diferentes: el mundo está compuesto de esta diversidad y los Estados 
no necesitan representar una sola nación. De ahí que el desafío político actual no sea la nación sino la posibilidad de acuerdos entre diferentes naciones.

\section{La responsabilidad como respuesta (Emmanuel Lévinas)}

Lévinas se pregunta cómo, en los regímenes totalitarios y en el transcurso de las guerras, los hombres de la modernidad han permanecido pasivos ante la expresión del mal, del terror, ante Auswitz: ¿cómo los hombres han podido tolerar un tal sufrimiento? Según el autor, la religión y la filosofía occidental moderna, movidas por su convicción de ser el camino hacia la verdad y el absoluto, han justificado el sufrimiento del hombre. En efecto, el fin de los tiempos, el juicio final, el ideal del comunismo, la Revolución, el progreso de la humanidad son otras tantas ideas, gracias a las cuales los seres humanos toleran el sufrimiento y justifican el mal. Según el hombre moderno, el sufrimiento es necesario para asegurar una vida futura, más allá del mundo sensible. Sufrir sin un motivo no tendría por consiguiente sentido, y por eso es contando con la promesa de un final feliz, que el hombre tolera el sufrimiento.

El pensamiento moderno aceptó, pues, el sufrimiento como característica esencial de la vida. Sin embargo, para Lévinas, todo este sufrimiento tolerado por la filosofía de Occidente no es más que un sufrimiento inútil. Para Lévinas aceptar el sufrimiento ha consistido en identificar los seres humanos con la pasividad, la soledad, la impotencia, el abandono. Según Lévinas, el siglo XX es la expresión de una actitud que puede expresarse en una sola fórmula: "cómo nos abandonamos al sufrimiento" (Lévinas, 1991: 107).

Por eso, es necesario cambiar el paradigma moderno. Así, Lévinas piensa que el mal exige una respuesta humana. La respuesta al mal no puede ser la espera, la pasividad: el horror del mal exige, sobre todo, una respuesta ética y, en este sentido, una ética de la responsabilidad.

La cuestión que entonces se plantea es saber cómo pensar la responsabilidad en cuanto posibilidad de todo ser humano. En la fenomenología de Lévinas la respuesta está dada por la experiencia de lo que significar ver el rostro del otro: el otro quiebra mi subjetividad, el otro me saca de mi mismo. Según Lévinas, la solución para el hombre moderno encerrado en sus pensamientos es encontrar a otro, que siempre pensará de manera diferente, que será diferente 
puesto que no es parte de mi historia, de mi mentalidad, de mi cuerpo, de mi vida. El otro me permite descubrir, dice el filósofo, que existe el infinito y que la totalidad es una construcción subjetiva, hecha por mi pensamiento. El rostro del otro paraliza mis poderes, mis pretendidas ideas universales. Así, para el filósofo, la resistencia a la totalidad está dada por el infinito. Y mirando al otro, en el fondo de sus ojos, yo comprendo sin defensas, con desnudez y miseria, que no puedo asimilar otro a mi pensamiento (Lévinas, 1987: 213).

Siguiendo Lévinas, el rostro del otro es el que me interpela éticamente: "el rostro me exige y me ordena" (Lévinas, 1992: 94). La interacción humana, por consiguiente, me saca de mi estadio subjetivo, la expresión del otro es lo que me ordena servirle. En este sentido, soy responsable del otro. Así pues, en la ética de Lévinas yo me hago responsable del mal porque el horror frente a él, frente a la expresión del sufrimiento que nace en el rostro del otro, exige de mí una actitud: hacerme responsable del sufrimiento de los otros es la única manera de actuar frente al mal. "El no matarás es también el sentido del rostro; en esta rectitud de la exposición, la proclamación -antes de todo signo verbal-de un derecho que en seguida me llama a mi responsabilidad para el otro hombre. Me asigna y me reclama como si la muerte invisible a la cual se enfrenta el rostro del otro - unicidad separada de todo conjunto- era asunto mío". Lévinas continúa: “... como si la muerte de otro, antes de ser mi muerte, me mirara; y mostrada a mí en el rostro de esta exposición- yo me vuelvo por mi indiferencia el cómplice cuando yo podía ser algo" (Lévinas, 1995: 134).

En el campo ético, en el primado de la percepción, la historia del hombre descubre a los otros seres humanos como finitos. El mal, ya sea caos, orgullo, exceso, pecado tendrá siempre una respuesta ética. Entonces, éticamente, no responderíamos de la existencia de los otros si pensáramos solamente en términos de respeto y de tolerancia a las diferencias (que siempre dejan la posibilidad de la indiferencia). El rostro del otro, del hombre, de la mujer, de este ser humano racial y culturalmente diferente me obliga a una acción responsable: a un compromiso y de ahí a una política diferenciada. Lo que él necesita no es lo que yo necesito, y no puedo pedir lo que quiero para mí, sino para él. Puedo pensar otras políticas simplemente porque puedo comprender al otro y viceversa.

El postulado de Lévinas nos conduce a dos consideraciones políticas. En primer lugar, es preciso saber si todos los ciudadanos están realmente en las 
mismas condiciones y si tienen las mismas capacidades de participación política. Es decir, es necesario asegurarse si realmente más allá de la mirada legislativa que considera todos los sujetos iguales, los actores políticos tienen las mismas condiciones de decisión y de participación política, o si no hay ciudadanos que están atrapados por su propia historia de discriminación, y que por ello no pueden participar de igual manera.

En el caso del Perú, por ejemplo, es difícil decir que los individuos, que pertenecen a las poblaciones nativas (quechuas, aymaras, awajún, shipibas, boras, asháninkas u otras) son ciudadanos peruanos con la misma posibilidad de participación que los otros. Aunque la legislación lo afirma, las condiciones políticas de estos ciudadanos no son las mismas. La historia y la historiografía nos recuerdan contantemente que los ciudadanos indígenas han sido separados, durante el primer siglo de la República, de su condición de ciudadanos y de sus derechos políticos, que han sido los peruanos más sacrificados durante la guerra entre los años 1980 y 2000, y que hasta hoy gran parte de ellos vive en condiciones de pobreza extrema. En ese sentido, las condiciones de participación política para esta parte no son las mismas que para otros, que sí gozan de todos sus derechos y sí pueden desarrollar sus capacidades humanas. La ética de la responsabilidad exige asegurar la igualdad de condiciones políticas, culturales, económicas etcétera, entre los actores, para que la toma de decisión sea verdaderamente democrática.

En segundo lugar, una política que busque el respeto a la diversidad requiere la representación de todos los actores políticos. Es necesario garantizar la participación de todos los grupos, comunidades, pueblos que constituyen el mismo Estado. Pero esto no significa siempre que las personas de otra nación o pueblo se identifiquen siempre con ciertos representantes de su nación o de su cultura o de su grupo de pertenencia: un awajún podría representar los intereses de un pueblo Aymará, o un quechua los proyectos políticos de un castellanohablante, limeño. Los individuos de una nación pueden ver sus intereses muy próximos a los intereses de otra nación, puesto que, como se ha visto anteriormente, el Estado es una organización con un proyecto colectivo en el que convergen diferentes identidades.

Con las consideraciones éticas de Lévinas, el proyecto de Estado no es una justificación de los intereses de cada nación; es un proyecto de responsabilidad 
compartida, que implica un proceso de confianza y de respeto entre pueblos diferentes, que implica un largo proceso de interculturalidad, es decir de ponernos en actitud de comprender y de valorizar lo que otro pueblo considera como importante, de reconocer que los valores de los otros son tan importantes como los míos. El resultado de este proceso intercultural es el consenso político, que permite una constitución, una administración y una jurisdicción ética, que representan y definen el Estado como un proyecto plurinacional, un proyecto compartido y asumido por los diferentes pueblos que habitan el país.

Por un lado Arendt, por otro lado Lévinas, ambos ofrecen perspectivas de la ética importantes para iniciar una nueva lectura sobre las formas del Estado contemporáneo, que permiten la formación o la modificación de la acción política en el marco del reconocimiento de la plurinacionalidad. Las nociones éticas presentadas por estos dos filósofos podrían convertirse en valores comunes para que pudieran formarse nuevas identidades nacionales, capaces de "situar sus horizontes de significación", es decir, formar nuevas identidades capaces de dialogar y de comprender que la diferencia es un valor post-moderno: una realidad y un proyecto político (cfr. Gadamer, 1996).

\section{Otras dos condiciones: la memoria y los horizontes compartidos (Ch. Taylor)}

Hay que considerar que la preocupación por el reconocimiento es un nuevo tema en la filosofía y en la política. Taylor explica que el reconocimiento es una "necesidad vital contemporánea" descubierta gracias a la necesidad de los individuos contemporáneos de definirse ellos mismos como seres únicos y originales. Para Charles Taylor los hombres premodernos no se preocupaban de definirse a sí mismos, de manera individual y auténtica, el reconocimiento no era un problema: los hombres se reconocían y se definían en relación con la jerarquía social establecida y con el rol social que cada uno ocupaba. "Nuestros ancestros creían formar parte de un orden que les transcendía. En ciertos casos, se trataba de un orden cósmico, de una 'gran cadena del ser' en la cual los seres humanos figuraban a su vez entre los ángeles, los cuerpos celestes y las otras criaturas terrestres. Este orden del universo se reflejaba en las jerarquías de la sociedad humana" (Taylor, 1994: 10). 
El acontecimiento de la sociedad democrática, que abole la jerarquía social hace surgir paradójicamente un interés por el reconocimiento: los individuos quieren ser reconocidos por los otros como diferentes y particulares. ${ }^{9}$ De hecho, ahora, lo que preocupa a los individuos no es solo el hecho del reconocimiento como tal, sino más bien saber cómo se construye y cómo la necesidad que tenemos de reconocimiento se satisface:

La importancia del reconocimiento hoy es universalmente admitida bajo una forma u otra. Sobre el plan privado, todos estamos conscientes que nuestra identidad puede ser formada o deformada por nuestro contacto con 'los otros que cuentan'. En el plano social ponemos en práctica una política constante del reconocimiento de la igualdad. La evolución del ideal de la autenticidad los ha modelado a los dos, y el reconocimiento juega un papel esencial en la cultura que ha aparecido en su torno (Taylor 1994: 57).

Para este trabajo, lo que interesa es el terreno social y los tipos de reconocimiento que se ejercen en este nivel. Es cierto que algunos Estados contemporáneos han logrado establecer un concepto de reconocimiento formal y universal que se desprende de un pensamiento liberal y neutro ("para todos los individuos"). Actualmente ciertos países protegen y permiten la existencia de la diferencia, ya se trate de sexos, de raza, de lengua, de cultura y da a los individuos de diferentes culturas la misma categoría de ciudadanía y las mismas capacidades de elección.

Sin embargo, nos dice Taylor, el principio de igualdad o de dignidad no basta, porque lo que no hace es garantizar al nivel jurídico la protección de la identidad explicitada por los derechos del hombre. Promueve un reconocimiento universal, ciego a la especificidad identitaria, pero es incapaz de practicar un reconocimiento de la particularidad de cada grupo social. Es difícil, por ejemplo, reconocer a todos los ciudadanos como iguales, olvidando la situación de

9 Se puede decir que la Revolución Francesa y los derechos universales de la libertad, la igualdad y la fraternidad han eliminado un rasgo que caracterizaba el Antiguo Régimen: la significación del honor, el cual marcaba las preferencias y las desigualdades entre los hombres, pero otorgaba un lugar específico a cada persona. Así, el honor es suplantado por la significación de la dignidad de todos los individuos, compatible únicamente con una sociedad democrática, donde todos los individuos comparten el mismo status: la ciudadanía y la capacidad de elección individual. 
pobreza a la cual algunos están sometidos en cuanto ciudadanos de "segunda categoría".

Contra el universalismo "ciego" de la dignidad y de la igualdad ha nacido una política fundada en la diferencia. Aquí se encuentran, por ejemplo, políticas que permiten que los grupos antes no favorecidos puedan acceder más fácilmente a los empleos o a la universidad. Se instaura, entonces, una discriminación a la inversa, una discriminación positiva, que no satisface las contrapartes de la dignidad universal.

Según Taylor, la disputa sobre el tipo de reconocimiento que debe ser asumido por los Estados no está resuelto. De un lado, los partidarios de la dignidad tienen como fundamento la idea que todos los individuos son igualmente dignos de respeto en cuanto humanos. De otro lado, los partidarios de la diferencia piensan que el derecho universal de modelar y desarrollar la cultura debe estar presente en la política. Los dos modelos de política comparten el principio de igualdad y ambos se hacen reproches, ya sea porque el uno viola el principio de no-discriminación practicando la discriminación positiva, ya sea porque el otro es ciego a las diferencia y que en realidad es partidario de una sociedad hegemónica: la occidental.

En todos estos textos, Taylor toma posición. Para él la política de la dignidad es la más cruel y la más perturbadora de todas, porque no reconoce más allá de su universalismo, hay ciertas creencias que todas las culturas no comparten, pero que son parte de la situación cultural particular. Con todo, el problema del reconocimiento persiste y la disputa continua. El individuo necesita ser considerado en su diferencia y al mismo tiempo gozar de las mismas condiciones que los otros individuos. Es preciso comprender este problema a partir de una perspectiva más directamente ética, que implica un trabajo por parte de los Estados, que desean ser considerados como plurinacionales.

Lo que buscan los Estados definidos como "plurinacionales" va más allá de un principio de igualdad. Está condicionado por ciertas características asociadas al concepto de reconocimiento político: a. El lugar dado a la memoria en un país, para desarrollar un reconocimiento positivo de todas las nacionalidades; $b$. La capacidad de los actores políticos para definir la igualdad como horizonte de valores compartido entre los individuos de una nación. Estas dos condiciones del reconocimiento nos permiten ir más allá de las trampas, que consisten en quedar 
al nivel jurídico, el cual reposa siempre sobre la versión moderna de la igualdad del individuo. ${ }^{10}$ Tratemos ahora de explicitar mejor estas dos condiciones:

El lugar de la memoria en el reconocimiento. Más que una cortesía, el reconocimiento, dirá Taylor, es "una necesidad humana vital" (Taylor, 1992: 43). De hecho el papel del reconocimiento en las relaciones humanas es crucial para la formación de la identidad individual o colectiva. Dicho de otra manera, la constitución propia de nuestra identidad se hace en relación con los otros humanos, ellos son "donadores de sentido", que les da mi vida, como yo soy "el donador de sentido" de su vida. Esta característica "dialógica", que se da en todos los campos de nuestra vida (amorosa, familiar, social), se desarrolla también en la vida política: la identidad de un grupo humano en función de las relaciones con los otros grupos humanos: cómo los otros nos reconocen, cómo nos identifican, cómo nos definen.

El peligro de no beneficiarse de un reconocimiento "positivo" podría condicionar mi acción como agente político. "Una persona o un grupo de personas puede sufrir un perjuicio o una deformación real si la gente o la sociedad que los rodea les devuelven una imagen limitada, envilecida de ellos mismos El no-reconocimiento o el reconocimiento inadecuado pueden provocar un daño y constituir una forma de opresión, encerrando a algunas personas en una forma de ser falsa, deforme y reducida" (Taylor 1992: 42).

¿Qué ocurre si históricamente un grupo de ciudadanos no ha tenido reconocimiento o si han tenido un reconocimiento limitado por parte de otros grupos? Se puede tomar aquí el ejemplo de Perú: los pueblos indígenas no han gozado de un reconocimiento como ciudadanos. Durante el primer siglo de la República han sido percibidos como humanos "inferiores", ciudadanos de segunda categoría. Aunque esta situación haya sido revisada jurídicamente después de la Constitución de 1979 (con el derecho de voto y otorgamiento de los dere-

10 Hay que subrayar que las dos condiciones presuponen ya una institución de la democracia en los Estados plurinacionales. Es imposible buscar la igualdad del reconocimiento en países que no han podido asegurar esta primera condición. En el caso peruano, la fragilidad de la institución democrática hace aún complicado el trabajo de un verdadero reconocimiento.

11 Taylor habla siempre "de ausencia de reconocimiento", de "falso reconocimiento" y "reconocimiento". Para desarrollar un discurso más claro, prefiero llamar a este último "reconocimiento positivo" por oposición a los dos precedentes. "Reconocimiento" implica la valoración del otro en su diferencia. 
chos políticos), ni el Estado ni la mayoría de la sociedad civil han intentado reconstruir la memoria colectiva del país, pedir perdón a las víctimas, curar las heridas, construir un proyecto de Estado plurinacional.

Así se construye ahora la República: manteniendo una herida que no ha sido curada, el tiempo ha "institucionalizado" ciertos prejuicios y ha "consolidado" las divisiones socioculturales del país; de un lado, los no/mal reconocidos (los ciudadanos indígenas) no se sienten identificados en el proyecto del país, por otro, los portadores del reconocimiento (el Estado) no saben cómo hacer para "integrar" todas las sangres en un solo Estado. Cada grupo social está más interesado en tener poder que en pensar en un país como proyecto colectivo. El reconocimiento, por consiguiente, no implica tan solo un trabajo jurídico, conforme a la ley, sino también y sobre todo un trabajo de reconstrucción histórica, de apuestas y de diálogo entre las partes.

En este sentido, podríamos decir que el reconocimiento "positivo" del que habla Taylor es una condición para el desarrollo hacia un Estado plurinacional democrático. Tal reconocimiento implica un trabajo de memoria por parte de todos los actores, una reconstrucción histórica y un compromiso de cada actor político, para invertir la situación desigual existente entre los grupos. El lugar dado a la memoria es muy importante para comprender el papel que toman los grupos "no" reconocidos. Si la historia no logra cambiar de dirección, considerando un reconocimiento "positivo" (y todo lo que implica) para todos los grupos nacionales, difícilmente se podrá hablar de un "Estado" como proyecto plurinacional.

Los horizontes ineludibles y compartidos del reconocimiento. Otra condición del reconocimiento concierne a la concepción limitada del sistema democrático liberal actual, donde "la igualización ha promovido solo los derechos cívicos y el derecho al voto" (Taylor, 1992: 36). Igualmente los derechos culturales han ocupado un segundo lugar. Pero un país interesado por el buen funcionamiento de su democracia, y deseoso de promover un Estado plurinacional debe responder a la cuestión: ¿Qué es lo que funda la igualdad de los valores? Como dice Taylor, este tipo de democracia implica un reconocimiento recíproco del valor igual de las diferentes identidades.

¿Cómo lograr este reconocimiento? El autor encontrará en el discurso de la hermenéutica una idea que puede dar lugar a una norma en los campos ético 
y político (cfr. Gadamer, 1996). "Debe haber un acuerdo fundamental sobre los valores sin lo cual el principio formal de igualdad sería vacío o falseado. Podríamos reconocer la igualdad de palabra, pero eso no significa dada a menos que compartamos algo más. El reconocimiento de las diferencias, como la libertad de elección, exige un horizonte de significación, más aún un horizonte compartido" (Taylor, 1994: 60).

¿Qué significa un horizonte compartido? Para la hermenéutica, sobre ciertos planos de inteligibilidad que rebasan el plano de los sentimientos y de las certitudes, el horizonte designa un conjunto de significados al cual pertenecen mis valores, mis ideales y yo mismo. Me es imposible salir de mi horizonte y comprender los valores de los otros "simplemente". Según la hermenéutica, todas las opciones son partes del horizonte de significación al cual pertenezco. Por consiguiente, el horizonte está siempre ahí, detrás de mí, me sostiene, seamos o no consciente de ellos; nos transciende y es ineludible (Taylor, 1994: 49).

Los horizontes nos permiten también reducir la distancia de nuestros valores con los de los otros; el horizonte ineludible nos da una actitud, la de acercarnos a otros valores que -quizás- no tienen significación en nuestro horizonte. Esto se logra unificando de una cierta manera mis valores con los de los otros. "Para él, X es tan importante como Y es para mí, yo no puedo insertar en mi horizonte el valor X pero puedo comprenderlo". El descubrimiento de un horizonte de significado nos permite darnos cuenta que hay un ideal de la libre elección singular, pero -al mismo tiempo- que es posible compartir el horizonte, porque no puedo definirme más que considerando las diferencias entre yo y los otros. Es la diferencia que me permite reconocer la cualidad del valor de los otros y de acercarme a ellos.

Por consiguiente, estamos invitados a utilizar esta norma ética: compartir nuestro horizonte, mezclar horizontes. Esto permite, a posteriori, ampliar nuestro propio horizonte. A nivel político ello implica la capacidad de todos los actores políticos de desplazar sus horizontes de significación, la capacidad de cada uno de hacer reconocer el suyo. Así se hace una política que reposa sobre un movimiento de interculturalidad, de diálogo abierto al cambio y al enriquecimiento de la diferencia, a la multiplicación de los intercambios.

La posibilidad abierta por la puesta en práctica de esta condición ética permitiría instaurar un tejido cultural en el seno del cual la política, en lugar de 
limitarse a tolerar la diferencia y a establecer una igualdad individual moderna, buscaría la aproximación del reconocimiento de la diferencia. Es decir que la política tendrá más bien interés en establecer relaciones interculturales entre los diferentes actores políticos. Es el caso de los famosos debates de las políticas públicas educativas en Estados Unidos, donde los cursos de historia o de religión, por ejemplo, han sido cambiados para dar a los estudiantes las diferentes visiones del país tal y como son vividos por todos los actores. Es también el caso, cuando se da la posibilidad de que los ciudadanos hablen su propia lengua en las instituciones públicas (en un juicio, en un hospital).

Con esto, una política de discriminación positiva se justifica como la medida temporal, que gradualmente pueda nivelar los campos de elección para todos los actores, conservando y tomando en cuenta las diferencia entre las naciones de un país. También el acercamiento de los horizontes ofrece la posibilidad de no caer en la idea de que una cultura es más civilizada que las otras o superior a las otras.

Resumiendo, estos dos elementos (memoria y horizonte compartido) son requeridos para caracterizar una política plurinacional. Ello implica pues un trabajo de memoria compartida entre todos los pueblos, que componen el país, porque el proyecto político plurinacional no es posible más que revisando el sentido de la historia y considerando el conjunto de diferentes miradas, que diferentes actores sostienen sobre ésta. De otro lado, este tipo de política implica también la construcción de una norma, que supere el derecho de igualdad individual, una norma que se construye sobre el plano cultural. En la puesta en práctica de esta norma, los individuos pueden descubrir que están inscritos en horizontes ineludibles, para los cuales la única posibilidad política sería la acción de compartir el horizonte. Considerando estas dos condiciones para el reconocimiento, los Estados podrían hacerse plurinacionales al nivel institucional -práctica y no solamente al nivel constitucional.

En conclusión, es importante superar el paradigma de la política moderna todavía presente en los marcos de la política actual, como los que vive el Perú. Si los postulados liberales están fundados sobre los derechos de la igualdad entre los hombres y el respecto de las diferencias, es preciso trabajar para que se exprese la ambición de este reconocimiento en accione políticas viables, que gocen de una legitimidad más grande y que permitan medidas favorables al diálogo y al reconocimiento de los pueblos que conforman los Estados. Los 
derechos de los pueblos indígenas no son un tema pasado para la política liberal y contemporánea, son actuales y no están resueltos en la forma de los Estados, por ejemplo, latinoamericanos.

Los federalismos o los regionalismos funcionan en ciertos países que han sabido dialogar sobre la manera de organizar su forma de Estado. Pero los problemas de reconocimiento permanecen en países como España (con la nación vasca). Como Kymlicka ha sostenido, el problema del reconocimiento y del derecho de las minorías cae en las manos de autoritarios o de fanáticos, que ponen en peligro la democracia y la paz.

En Perú, a diferencia de Bolivia y Ecuador, los grupos minoritarios no han logrado una cohesión y organización que obligue al Estado a transformar su propia noción política. En algunos casos, la defensa de los pueblos ha sido llevada por ciertos grupos que piensan que las culturas son estáticas, como una pieza de museo y que hay que "respetarlas" en cuanto tal. Estos grupos políticos no reconocen que su propio surgimiento histórico, su propio desarrollo se ha efectuado a través del contacto con otras culturas y que sus elementos más autóctonos tienen ellos mismos diferentes orígenes. Por otro lado, muchos líderes políticos (muchos de ellos representantes y autoridades políticas) han intentado resolver el problema a partir del campo educativo, como si la representatividad y desarrollo del pueblo pudiera reducirse a la educación y a programas de preservación lingüística. El Estado peruano ha invertido parte del presupuesto para desarrollar escuelas bilingües interculturales en la educación básica regular, sin asegurar el uso legítimo de la lengua en otras instancias del Estado (por ejemplo, una atención hospitalaria en la lengua de origen, una asesoría jurídica en la lengua materna).

Con todo ello, se sigue reflejando en el Perú, que el poder del Estado (nación) se ha superpuesto al de la cultura particular y la discrimina invisibilizándola. No hemos visto hasta ahora, ni después de los sucesos de Bagua, cuáles son los procedimientos para que representantes de pueblos indígenas participen en la elaboración de sus programas educativos o en otras instancias. ${ }^{12}$ Por consiguiente, ni el Estado ni ciertos grupos defensores de poblaciones indígenas

12 No obstante, debemos reconocer como un gran avance la aprobación promulgación de la Ley de Consulta Previa de los Pueblos Indígenas u Originarios (2011). 
han podido resolver el problema de las discriminaciones culturales: de un lado, el Estado trabaja solo con los grupos discriminados, pero no con los grupos que discriminan (la población criolla y mestiza, por ejemplo); de otro lado, los "indigenistas" comienzan por desarrollar una defensa de los pueblos originarios, con presupuestos de discriminación a todo lo que no es como ellos. En ningún caso se piensa que la discriminación es una relación entre dos y que el reconocimiento implica otros valores sociales, el respeto, la responsabilidad, la aceptación de la diversidad. La historia del Perú nos habla de prejuicios y visiones peyorativas del Otro y no de un mutuo reconocimiento, ya que la historia (y la memoria) está marcadas por la diferencia de aquellos que tienen históricamente el poder y aquellos que no lo tienen.

Para el Perú, la acción política a favor de los derechos de los pueblos indígenas es una urgencia, no solo para preservar la democracia, sino también para legitimar su desarrollo y sus instituciones. No podemos hablar de legitimidad, si el valor de la diferencia cultural no es reconocido más que parcialmente o si no hay más que un tipo de actor que participa en el debate político. En este caso, no hay democracia ni tampoco legitimidad. 


\section{Bibliografía}

\section{Textos}

Arendt, Hanna. Condition de l'homme moderne. París : Calmman-Lévy. 1983.

De Rivero, Oscar. El mito del desarrollo, Lima: FCE. 2001.

Enegrén, André. La pensée politique de Hannah Arendt. Paris: Presses Universitaires de France. 1984.

Ferrajoli, Luigi. Derechos y Garantías. La ley del más débil. Madrid: Trotta. 1999.

Gadamer, Hans-George. Vérité et Méthode. Paris: Seuil. 1996.

Hobbes, Thomas. Leviatán o la materia, forma y poder de una república eclesiástica y civil. México D.D. FCE. 1984.

Honneth, Axel. La lucha por el reconocimiento. Barcelona: Crítica. 1997.

Kymlicka, Will. La citoyenneté multiculturelle. Paris: La Découverte. 2001.

Lévinas, Emmanuel. Totalidad e Infinito. Salamanca: FCE. 1987.

Lévinas, Emmanuel. "La souffrance inutile" en Entre nous, essais sur la pensée à l'autre. Paris : Bernard Grasset. p. 107-119. 1991.

Lévinas, Emmanuel. Éthique et Infini. Paris: Fayard. 1992.

Lévinas, Emmanuel. "Interdit de la représentation et droit de l'homme" en Altérité et Transcendance. Paris: Fata Morgana. 1995.

Mill, John Stuart. Le gouvernement représentatif, Paris: Guillaumin. 1972.

Rawls, John. Théorie de la justice. Londres: Oxford Université Express. 1971.

Rawls, John. Derecho de gentes. Madrid: Paidós. 2006.

Taylor, Charles. Multiculturalisme, différence et démocratie. Paris: Champs Flammarion. 1992a.

Taylor, Charles. Rapprocher les solitudes. Sainte-Foy: Université Laval. 1992b.

Taylor, Charles. Le malaise de la Modernité. Paris: Cerf. 1994.

Villoro, Luis. Estado Plural, pluralidad de culturas. México: Paidós. 1999.

Weber, Max. Le savant et la politique. Paris: UGD. 1971. 


\section{Sitios Web}

Etxebarria, Xavier. Derechos humanos y participación social en el marco de la interculturalidad en Ridei<www.pucp.edu.pe/invest/ridei/pdfs/ participacion-multicul.pdf $>$ [4 de setiembre de 2006].

Manrique, Nelson. Multiculturalidad y cuestión nacional en Palestra $<\mathrm{http} / /$ palestra.pucp.edu.pe/pal_est/?file=cultura/manrique.htm $>$ [4 de agosto de 2006] 2001.

Tubino, Fidel. "Interculturalismo latinoamericano y Estados nacionales" en Ridei: <http://www.pucp.edu.pe/invest/ridei/b_virtual/archivos/Tubino_ intercullatinoamericano.pdf $>$ [6 de agosto de 2006]. 2004.

Woehrling, José " Fédéralisme et protection des droits fondamentaux 》 en Troisième Conférence Internationale sur le Fédéralisme. Bruxelles, mars 2005. $<$ www.federealis2005.be/com/attachement/i/479> [6 de agosto de 2006].

Wieviorka, Michel. "Diferencias culturales, racismo y democracia" en Ridei $<$ http://www.pucp.edu.pe/invest/ridei/b_virtual/archivos/Wieviorka_ diferencias.pdf $>$ [6 de agosto 2006].

Envío 6 de septiembre/2011 - Aceptación 17 de noviembre/2011 